\title{
Panfletos publicitários como material didático na EJA: uma proposta transdisciplinar
}

\author{
Brochures as didactic material in the EJA: a transdisciplinar proposal
}

\begin{abstract}
Clênia Borges de Rezendeㄹ Dilma Maria Coêlho'ㄹ, Joir Benedito Proença de Amorim² e Lucy
Ferreira Azevedo ${ }^{3}$

${ }^{1}$ Graduada, Instituto Federal de Educação, Ciência e Tecnologia de Mato Grosso - Campus São Vicente - Núcleo Avançado de Jaciara, MT, Brasil.

${ }^{2}$ Mestre em Educação, Instituto Federal de Educação, Ciência e Tecnologia de Mato Grosso - Campus São Vicente - Núcleo Avançado de Jaciara, MT, Brasil.

${ }^{3}$ Doutora em Língua Portuguesa, Departamento de Pós-Graduação, Universidade de Cuiabá - UNIC, Cuiabá, MT, Brasil
\end{abstract}

\section{Resumo}

Apresentar análise e relato da aplicação de um instrumento comum, conhecido popularmente como panfleto publicitário utilizado como recurso no processo ensino aprendizagem e como norteador de uma proposta transdisciplinar para os alunos e a priori para os professores da (Educação de Jovens e Adultos) EJA. Sendo apresentada como uma proposta metodológica encaminhada como caráter de intervenção pedagógica realizada na Escola Estadual de Ensino Fundamental e EJAAntonio José de Lima. Objetivou-se avaliar a possibilidade de um planEJAmento participativo, respeitando o Projeto Político Pedagógico(PPP) da instituição e os planos de Ensino dos Professores. Fundamentou-se em autores que investigam o tema e em documentos como o PPP e os Parâmetros Curriculares Nacionais (PCNs); Buscouse apresentar e conceituar o que vem a ser transdisciplinaridade e interdisciplinaridade. Temas estes, que muito trazem dúvidas e desencontros de conceitos e, até mesmo certa inquietação por parte dos docentes e toda a comunidade escolar. Embora a proposta tenha sido recebida como um desafio por toda a equipe, após reuniões, estudos, planEJAmento e posteriori aplicabilidade, pode-se dizer que o resultado correspondeu às expectativas haja vista que os envolvidos constataram que a experiência lhes proporcionou analisarem a possibilidade de fazer acontecer e tornar a experiência como uma práxis na modalidade.

Palavras-chave: Panfleto publicitário. Processo ensino-aprendizagem. EJA. Transdisciplinaridade

\begin{abstract}
Present analysis and reporting of the implementation of a common instrument, popularly known as Rack used as a resource in the teaching and learning as a guiding transdisciplinary proposal for students and teachers prior to the EJA. Being presented as a methodology referred to as character pedagogical intervention performed in the State School Antonio José de Lima. The objective was to evaluate the possibility of participatory planning, respecting the Pedagogical plans Teaching Teachers Political Project of the institution. Was based on authors who researched and documents such as the PPP, NCPs; Sought to present and conceptualize what is being disciplinarity these topics that bring much doubts and misunderstandings of concepts and even some anxiety on the part of teachers and the whole school community. Although the proposal has been received and as a challenge for the whole team, and after meetings, studies, planning and posteriori applicability, it can be said that the result met expectations given that those involved found that the experience gave them analyze the possibility of a new pedagogical proposal happen.
\end{abstract}

Key-words: Rack. Teaching-learning process. EJA. Transdisciplinarity 


\section{Introdução}

Desde a catequese jesuítica na colonização do Brasil, a atenção voltada para a educação do adulto vem passando por movimentos nem sempre bem sucedidos para capacitar o homem para o mundo do trabalho no contexto rural ou urbano industrial. E ,assim,todos os sinais dados pela História mostraram que esta era a perspectiva da educação: forma direcionada para o servir, a existência concreta do homem que excluía suas subjetividades e processos de interação no coletivo.

Fórmula certa para a insucesso, esta perspectiva, no entanto, denuncia o quanto a Educação de Jovens e Adultos de todo o Brasil exigia e exige ações que ofereçam desafios muito além do livro didático, pois o universo destes estudantes é amplo, eles possuem um repertório de representações, conhecimentos intuitivos, adquiridos pela vivência, pela cultura e senso comum, acerca dos conceitos que serão ensinados na escola. Também,o grau de amadurecimento intelectual e emocional do aluno e sua formação escolar são relevantes na elaboração desses conhecimentos prévios.

Assim, ao refletir sobre diálogo entre alunos de curso de especialização do IFMT, professor e aluno da EJA, este artigo pretende relatar uma experiência com panfleto como material didático para jovens e adultos, experiência desenvolvida na Escola Estadual de Ensino Fundamental e EJA Antonio José de Lima, em Juscimeira, Mato Grosso.

Depois de um breve apanhado sobre o que não aconteceu de substancioso na realidade brasileira em termos de EJA, mesmo estando no papel, estão alinhados conceitos que responderiam, ao entender dos pesquisadores, à proposta de fazer aulas mais motivadoras e de algum impacto no cotidiano dos alunos tão particularmente sacrificados pela sua existência não levada em consideração.

E, para sustentar as discussões, os autores principais foram Paulo Freire, Paulo Ronca, G.Michaud, E.Jantsch e J. Piaget.

Refletir, portanto, sobre o panfleto como material atraente e instigador para este aluno que chega com uma série de limitações e, especialmente, cansado, é a proposta deste artigo, porque é um comunicativo volante que cotidianamente chega à porta de cada cidadão como informativo, propaganda,convite,etc.Configura-se como uma comunicação que está atrelada ao presente.É a necessidade que se apresenta no aqui e no agora.

Ao se propor uma situação metodológica com um conceito muito discutido, estudado e desafiador até mesmo pelo fato do mesmo ser proposto para uma modalidade como a EJA, é que os professores apresentam ansiedades e desejos de fazer o melhor.

\section{História e Paradigma}

Passando-se pelo traço histórico, tem-se então,em 1934, a Constituição Federal que estabeleceu a educação de adultos como dever do Estado,incluindo em suas normativas o Ensino Fundamental, gratuito com frequência obrigatória.

Muitas campanhas seguiram-se e,em 1962,a Lei de Diretrizes e Bases da Educação Nacional (LDBEN) promulgou o Plano Nacional de Educação (PNE), já com influência de Paulo Freire que via a necessidade de reconhecer, em qualquer plano para educação de adultos, a cultura deste cidadão, sua cultura e identidade.

Passa-se o período ditatorial e somente em 1996, a LDB 9394-96, surge com o EJA nos moldes que conhecemos e, em 2000, o CNE, com as Fundações da EJA, estabelecem-na como: reparadora, equalizadora e qualificadora. Em Mato Grosso, foi criada com três segmentos pelo Conselho Estadual de Educação de Jovens e Adultos, da Secretaria Estadual de Educação de Mato Grosso: anos iniciais do Ensino Fundamental em três fases; anos finais do Ensino Fundamental,também com três fases e Ensino Médio, dos 14 aos 18 anos.

Sabendo-se que o público-alvo é diferenciado, pensou-se em um paradigma possível para equacionar uma realidade tão dferenciada. Assim, a transdisciplinaridade é um paradigma que se fez necessária e estudá-la e compreendê-la foi o início. Em diálogos não formais, inferiu-se a não 
compreensão ou definição do conceito, por isso, apresenta-se, para fins de esclarecimentos, as definições de interdisciplinaridade e transdisciplinaridade de acordo com alguns autores citados na Revista Práxis (2012), demonstrados na tabela 1.

A transdisciplinaridade está ligada à epistemologia desencadeada pela física no início do século XX. Este conceito, transdisciplinaridade foi enunciado pela primeira vez por Jean Piaget, como lido e analisado conforme o quadro anterior,quando deu continuidade ao estudo interdisciplinar a partir de um método mais complexo que seria a transdisciplinaridade e foi juntamente com a palavra "holística" que o termo se tornou conhecido. Uma nova transdisciplinaridade com um paradigma que permite ao mesmo tempo, a distinção, separação ou mesmo a oposição, isto é, a disjunção destes domínios científicos, mas que possa fazê-los comunicar sem operar a redução (Revista Práxis, 2012).

Tabela 1 - Definições de interdisciplinaridade e transdisciplinaridade de acordo com alguns autores citados na Revista Práxis (2012)

\begin{tabular}{|c|c|c|c|}
\hline & G.Michaud & E. Jantsch & J. Piaget \\
\hline Interdisciplinaridade & $\begin{array}{l}\text { Interação existente entre duas ou } \\
\text { mais disciplinas. Essa interação } \\
\text { pode ir de simples comunicação } \\
\text { de idéias à integração mútua dos } \\
\text { conceitos diretores da } \\
\text { epistemologia, da terminologia, } \\
\text { da metodologia, dos } \\
\text { procedimentos, dos dados da } \\
\text { organização referentes ao ensino e } \\
\text { à pesquisa. Um grupo } \\
\text { interdisciplinar compõe-se de } \\
\text { pessoas que receberam sua } \\
\text { formação em diferentes domínios } \\
\text { do conhecimento (disciplina) com } \\
\text { seus métodos, conceitos, dados e } \\
\text { temos próprios (MICHAUD, } 1972 \\
\text { apud FAZENDA, 1996, p.27). }\end{array}$ & $\begin{array}{l}\text { Destina-se a um sistema de } \\
\text { dois níveis e de objetivos } \\
\text { múltiplos onde há } \\
\text { coordenação procedendo } \\
\text { do nível superior } \\
\text { (JANTSCH, } 1972 \text { apud } \\
\text { FAZENDA, 1996, p. 38). }\end{array}$ & $\begin{array}{l}\text { Segundo nível de associação entre } \\
\text { disciplinas, em que a cooperação } \\
\text { entre várias disciplinas provoca } \\
\text { intercâmbios e, consequentemente, } \\
\text { enriquecimentos mútuos (PIAGET, } \\
1979 \text { apud SANTOMÉ, 1998, p. 70). }\end{array}$ \\
\hline Transdiciplinaridade & $\begin{array}{l}\text { Resultados de uma axiomática } \\
\text { comum a um conjunto de } \\
\text { disciplinas (ex. Antropologia } \\
\text { considerada como "a ciência do } \\
\text { homem e de suas obras", segundo } \\
\text { a definição de Linton) } \\
\text { (MICHAUD, } 1972 \text { apud } \\
\text { FAZENDA, 1996, p. } 27 \text { ). }\end{array}$ & $\begin{array}{l}\text { Coordenação de todas as } \\
\text { disciplinas e } \\
\text { interdisciplinas do sistema } \\
\text { de ensino inovado, sobre } \\
\text { base de uma axiomática } \\
\text { geral - destina-se a um } \\
\text { sistema de nível e objetivos } \\
\text { múltiplos - há coordenação } \\
\text { com vistas a uma } \\
\text { finalidade comum dos } \\
\text { sistemas (JANTSCH, 1972 } \\
\text { apud FAZENDA, 1996, p. } \\
\text { 38). }\end{array}$ & $\begin{array}{l}\text { É a etapa superior de integração. } \\
\text { Trata-se da construção de um } \\
\text { sistema total, sem fronteiras } \\
\text { sólidas entre as disciplinas, ou } \\
\text { sEJA, de "uma teoria geral de } \\
\text { sistemas ou de estruturas, que } \\
\text { inclua estruturas operacionais, } \\
\text { estruturas de regulamentação e } \\
\text { que una estas diversas } \\
\text { possibilidades por meio de } \\
\text { transformações reguladas e } \\
\text { definidas" (PIAGET, 1979 apud } \\
\text { SANTOMÉ, 1998, p. 70). }\end{array}$ \\
\hline
\end{tabular}

O conceito de transdisciplinaridade geralmente sugere um pensamento que algo muito radical ocorrerá, mas ela ocorre nos pequenos detalhes onde nem mesmo se percebe o seu acontecer. A conexão dos saberes e a exploração desses de uma forma simples como um material tão comum é, particularmente, um instrumento motivador para novos estudos com outros temas, principalmente quando a turma envolvida faz parte de um grupo de pessoas com um considerado conhecimento de mundo. A saber: segundo seguimento da EJA. Paulo Ronca em (entrevista a revista Nova Escola) explica que a transdisciplinaridade é um contexto amplo, mas não impossível e já há algum tempo vem estudando sobre o assunto em questão. 


\begin{abstract}
Transdisciplinaridade, porém, é um conceito que surgiu há algumas décadas. Jean Piaget o utilizava para referir-se a um estágio superior das relações entre as disciplinas na escola. Se cada disciplina segue uma metodologia e se cada conhecimento desvenda uma pequenina parte da verdade mais ampla, a transdisciplinaridade busca o que é comum em todos os pensares, o lugar onde todas as ciências convergem, para que possamos entender a relação do homem com o mundo. O objetivo dessa postura no educar é o de acolher e compreender o mundo como ele se apresenta, com sua história e suas possibilidades. A transdisciplinaridade é o fim da visão individual e mecânica, simplista por nascença. A rigidez imposta na divisão das ciências, a inflexibilidade adotada em aula e a severidade de nossas concepções só levaram ao empobrecimento de idéias e à exclusão social. O jovem hoje é atingido por densos estímulos visuais, a noção de tempo e de espaço mudou drasticamente e a iminência de uma guerra bacteriológica contrasta, por exemplo, com as facilidades que nos traz a informática "(Revista Nova Escola).
\end{abstract}

O desafio assumido pelos estagiários e a equipe escolar da Instituição de Ensino supra citada consiste em romper com a visão individual e mecânica daquilo que se propôs, em especial na modalidade de Educação de Jovens e Adultos e essa atitude vem ao encontro da necessidade de quebrar uma barreira que, muitas vezes, aparece pela falta de uma formação inicial e também na formação contínua dos professores que atuam nessa modalidade e, pelo fato de os alunos se sentirem deslocados daquilo que se estuda fragmentadamente, o que faz com que os mesmos se sintam desmotivados por não conseguirem construir conhecimento a partir da própria riqueza de vida no mundo e do mundo no qual estão inseridos,conforme ressalta o documento construído pela própria escola, considerado suporte para as ações escolares.(PPP-2010)

Uma tentativa de apresentar e fazer acontecer uma nova proposta que venha contrapor o contexto e a formação do epistemicídio, que ditam regras, conceitos e atitudes, ou seja, o anti-dialógico, conhecido como educação bancária, propondo um pensar transdisciplinar.

O "ensino bancário (FREIRE, 1996, pg. 25) precisa ser recusado, extirpado do que chamamos de educação, afinal, ele "(...) deforma a necessidade da criatividade do educando e do educador (...)" (idem). A partir dessa concepção de ensino, os estudantes apenas copiam em suas mentes os conceitos dados, não aprendem a aprender, tendo sua capacidade de pensar que é ilimitada, reclusa a um conjunto de pensamentos pré estabelecidos por um sistema que propositalmente os faz, a fim de facilitar o seu domínio sob os que fazem parte da sociedade por ele criada ou imposta. Educar exige que os professores respeitem os educandos. “(...) construídos na prática comunitária (FREIRE, 1996,pg. 30) e discutam com eles relação com o conteúdo ensinado na sala de aula, o que, inevitavelmente, leva ao ensino transdisciplinar sobre o qual será discutido.

Transmultinacionais, rapidação, lei do mercado, termos estes que acompanhados pela universalização dos saberes, que não deixam de serem fatores de formas de apropriações capitalistas para melhor controle de uma humanidade ideologicamente envolvida em seres consumidores tecnologicamente alienados, tendo a sua centralização em um órgão legitimado e organizado pelas Nações Unidas denominada UNESCO que, em apoio à construção da Carta da Transdisciplinaridade no Primeiro Congresso Mundial de Transdisciplinaridade (Portugal: Convento de Arrábia, 1994) vem a trabalhar paradigmas de acordo com os pensamentos de vários precursores da idéia transdisciplinar, afirmou a necessidade do não reducionismo do saber. Estes novos pensamentos foram instituídos graças a Multi, Inter e Transdisciplinaridade. Para Weil (1993), a importância dos conhecimentos "leva o transdisciplinar para todas as áreas da vida humana, incluindo a parte espiritual, conseqüentemente chegando a visão holística, que defende a compreensão integral dos fenômenos e do ser humano buscando tudo abranger".

A transdisciplinaridade pode ser interpretada como uma postura diante da vida. É a atitude de abertura ao diálogo e ao compartilhamento de ideias, pensamentos, opiniões, emoções e sentimentos, "ela tem como fundamentos a complexidade, a lógica primária e a multidimensionalidade do mundo" (NICOLESCU apud ANTONIO, 2002). É a própria vida acontecendo simultaneamente em todas as etapas. É uma contínua experiência que provoca estímulos para se desafiar como indivíduo, como um ser complexo, mas não só na individualidade, pois não se faz e/ou vive processos educacionais sozinho. Baseia-se num conjunto de ações e planEJAmentos compartilhados e direcionados a um ensino onde se valoriza a vida em todos os seus conhecimentos. 
Para Severino (1996), "a transdisciplinaridade estabelece um conjunto de práticas e deve-se ter curiosidade para conhecer ideias e propostas novas, fazer de maneira democrática, o melhor paradeterminada situação e claro, deve-se ser, saber e fazer". É estar disposto a buscar, a se questionar sobre sua forma de compartilhar conhecimentos, é se desafiar à procura de novas ideias, e ouvir, e se permitir a ser avaliador e analisador de si próprio, dos seus fazeres e dos seus saberes.

Tanto os Parâmetros Curriculares Nacionais, quanto as Orientações Curriculares direcionam o ensino nas suas diversas áreas do conhecimento para um ensino contextualizado, compropostas inter e transdisciplinares. Embora os documentos oficiais e as obras que tratam do fazer pedagógico tenham representativos avanços no sentido de ampliar tais abordagens, caracteriza-se, ainda, a necessidade de transpor uma formação tradicional, e romper com a individualidade que mesmo o projeto sala do professor e hoje sala do educador conseguiu. Daí o desafio. É possível acontecer uma proposta pedagógica com materiais comuns do dia a dia de onde se pode absorver ou extrair uma imensa gama de informações científicas muitas vezes camufladas dentro de um material simples como, por exemplo, em uma horta, na construção de uma casa, com alimentos, panfletos publicitários, e não mais de maneira arcaica que se prega conhecimentos, mas é necessário que haja uma abertura de possibilidades de se atingir um compartilhamento de conhecimentos de forma a estreitá-los procurando compreender as suas interligações.

Em 1994, em Arrábida- Portugal, aconteceu o I Congresso Mundial de Transdisciplinaridade com a importante colaboração do CIRET-Centre International de Recherches et d’Études Transdisciplinares e apoio da UNESCO que apresenta uma clara definição sobre o conceito transdisciplinar em sua Carta da Transdisciplinaridade:

Artigo 3: “(...) A Transdisciplinaridade não procura a dominação de várias disciplinas, mas a abertura de todas as disciplinas que as atravessa e as ultrapassa."

Artigo 7: "A Transdisciplinaridade não constitui nem em uma nova religião, nem em uma nova filosofia, nem uma nova metafísica, nem uma ciência das ciências".

O homem em sua origem é configurado para se desenvolver de maneira transdisciplinar, pois o próprio é constituído, em sua essência pelas naturezas biofísica, cósmica e seu viver correlaciona em todas as grandezas. Segundo( Akiko Santos), "na vida, somos todos 'transdisciplinares', mas quando colocamos os pés nas salas de aula, somos disciplinares." Não é o pensar individual em suas particularidades que leva a uma resolução, é necessário um entrelaçar de pensamentos para acontecer um desfecho real em sua totalidade, um conjunto de esclarecimentos que levem a um determinado ponto da questão.É apenas um diferencial pedagógico aplicado, procurando valorizar o que o indivíduo já adquiriu no seu viver de forma integrada com a ciência e não uma transformação radical para revolucionar o espaço escolar nem a sua equipe. Na verdade, neste momento acontecem maior integração e aproximação da equipe envolvida e não uma ruptura por partes fragmentadas.

Em conformidade com os PCNs, um dos objetivos da sua proposta é a formação de um cidadão crítico que exige sua inserção numa sociedade em que o conhecimento científico e tecnológico é cada vez mais valorizado. Neste contexto, o papel das Ciências Naturais é o de colaborar para a compreensão do mundo e suas transformações, situando o homem como indivíduo participativo e parte integrante do Universo. Os conceitos e procedimentos desta área contribuem para a ampliação das explicações sobre os fenômenos da natureza, para o entendimento e o questionamento dos diferentes modos de nela intervir e, ainda, para a compreensão das mais variadas formas de utilizar os recursos naturais. Isso se torna mais relevante quando este procedimento acontece numa modalidade de ensino onde há tamanha amplitude de saberes. O ensino de Ciências para esta modalidade deve abranger muito além do que traz ou apresentam os livros didáticos. É necessário buscar algo que integre seus conhecimentos com as ciências, buscando uma melhor compreensão e aproveitando de seus saberes com o que a escola lhe apresenta o que, consequentemente, será mais viável para que se estabeleça uma conexão mais abrangedora no ensino/aprendizagem.

É muito relevante pautar-se por uma criticidade desenvolvida pelos meios de participação, interação, vivências de educações, o sujeito se motivando por meio daquilo que antes era considerado 
apenas senso comum, mas que era todo o conhecimento que o tal sujeito se referia. O conhecimento prévio se torna parte, material de estudo, observação, aproveitamento como base, como ponto de partida para o científico.

Para alicerçar este estudo e a intervenção apresentada, buscou-se orientação em documentos oficiais do MEC, que norteiam o ensino brasileiro, fazendo uma retrospectiva histórica para que nestes possam justificar as propostas do uso do instrumento e da produção de uma construção do que muitos ainda não possuem clareza no fazer pedagógico que é a transdisciplinaridade.

Até a promulgação da Lei de Diretrizes e Bases (LDB) n. 4.024/61, ministravam-se aulas de Ciências Naturais apenas nas duas últimas séries do antigo curso ginasial. Essa lei estendeu a obrigatoriedade do ensino da disciplina a todas as séries ginasiais. Apenas a partir de 1971, com a Lei n. 5.692, Ciências Naturais passou a ter caráter obrigatório nas oito séries do primeiro grau. A inserção do ensino de Ciências nos primeiros anos do ensino fundamental traz a possibilidade de uma aproximação instigadora sobre as origens, evoluções, pesquisas, abrindo novos olhares para o meio científico daquilo que lhe era tão comum. $\mathrm{Na}$ atual conjuntura, com todas as inovações técnico/científicas, a introdução do estudo das Ciências Naturais permite que o aluno compreenda, assimile, compare, questione e pesquise cada vez mais sobre o que lhe provoca uma busca por um mundo ainda não explorado.

De um lado, os estudantes possuem um repertório de representações, conhecimentos intuitivos, adquiridos pela vivência, pela cultura e senso comum, acerca dos conceitos que serão ensinados na escola. O grau de amadurecimento intelectual e emocional do aluno e sua formação escolar são relevantes na elaboração desses conhecimentos prévios. Além disso, é necessário considerar, o professor também carrega consigo muitas ideias de senso comum, ainda que tenha elaborado parcelas do conhecimento científico. De outro lado, tem-se a estrutura do conhecimento científico e seu processo histórico de produção, que envolve relações com várias atividades humanas, especialmente a Tecnologia, com valores humanos e concepções de Ciência.

Quando o indivíduo começa a trilhar, de forma simultânea, dois caminhos de conhecimentos automaticamente, irá confrontar-se com o que havia adquirido anteriormente, inclusive consigo mesmo, pois a ciência instiga e desafia aquilo que já se conhecia e questiona sempre suas veracidades investigando se há comprovações suficientes para que sEJAm aceitas como fato.

As ciências se envolvem de tal forma no cotidiano do aluno que o levam a analisar sob outros olhares assuntos cotidianamente tratados de maneira que não se observa a cientificidade inserida no mesmo, mas que, a partir do momento que ele se integra ao meio científico, é que ele vai assimilar ou confrontar seus conhecimentos.

O tema transversal Meio Ambiente traz a discussão a respeito da relação entre os problemas ambientais e fatores econômicos, políticos, sociais e históricos.

São problemas que acarretam discussões sobre responsabilidades humanas voltadas ao bem-estar comum e ao desenvolvimento sustentado, na perspectiva da reversão da crise socioambiental planetária. Sua discussão completa demanda fundamentação em diferentes campos de conhecimento. Assim, tanto as ciências humanas quanto as ciências naturais contribuem para a construção de seus conteúdos.

É neste momento que se faz necessário abranger o termo científico e o denominado senso comum, pois não se deve desconsiderar o cotidiano dos alunos, mas aproveitar desses viveres mostrando e/ou demonstrando as ciências que envolvem o seu dia a dia.

\section{Material e Métodos}

\subsection{Materiais}

Panfletos Publicitários de Móveis e Eletrodomésticos, giz, lousa, data show, dado, papel sulfite, canetão, computador, pedaços de MDF e MDP, laranjas. 


\section{2 métodos}

Como fundamentações foram usados alguns teóricos e documentos oficiais que norteiam a educação, como os PCNs, O PPP da Escola Estadual de Ensino Fundamental e EJA Antonio José de Lima bem como os objetivos propostos para esta Modalidade de ensino (EJA).

Num primeiro momento, foi solicitado à direção e coordenação da Escola pelos estagiários a oportunidade de desenvolverem uma atividade de intervenção pedagógica que faz parte do componente curricular do curso de Licenciatura em Ciência da Natureza;marcada uma reunião com essa equipe, apresentou-se a proposta para os docentes que a receberam como uma inovação em seus trabalhos e já começaram a planEJAr de que forma poderiam estar introduzindo o material sem interferir nos seus planEJAmentos, mas sim o integrando aos mesmos; começaram as análises de diferentes temas;intensificaram-se os trabalhos entre professores e estagiários com a presença da supervisão e do orientador do TCC.

Cada professor estudou os panfletos e focou sua área de saber:Matemática: o conceito abordado foi a porcentagem; Ciências Humanas e Sociais- Geografia: trabalhando o tema Participação Social; História: o tema abordado nesta disciplina foi o Feudalismo.Sociologia: conduzida pelo pensamento de Abraham Lincoln que "O caráter é uma árvore e a reputação como a sombra. A sombra é o que nós pensamos dela; a árvore é a coisa real", a professora de ensino religioso direcionou sua aula para a observância das opções que o ser humano faz para si em conformidade com a sua personalidade, seu jeito de viver e de agir em meio à sociedade na qual está inserido;Código e Linguagem: as várias formas de linguagens apresentadas por um panfleto publicitário foram abordadas nesta disciplina quando a professora introduziu o tema Aspectos da Linguagem, proporcionando aos alunos observarem que muitas informações importantes para o consumidor ficam subentendidas ou até mesmo em segundo plano.

Quando se fala em transdisciplinaridade,assim, aflora uma ansiosa expectativa de vivenciar uma transformação avassaladora no ensino. Numa perspectiva de práxis transdisciplinar são necessárias as visões ampliadas que sensibilizem para que aconteça uma estreita ou camuflada relação entre compreensão da percepção e atividade realística tanto da parte da equipe gestora como dos docentes e alunos que devem ser instigados a analisar as sutis interconexões que existem nas particularidades do processo ensino-aprendizado, segundo os Parâmetros Curriculares Nacionais.

O ensino embora tenha avançado no sentido de ampliar tais abordagens, caracteriza-se, ainda, por sua forma tradicional, onde as propostas inter e transdisciplinares aparecem na maioria das vezes de forma camuflada, discreta, sem causar o impacto necessário para que os educadores percebam a importância de tais perspectivas na educação para a ciência (BRASIL, 1999).

Neste sentido, os pequenos detalhes que diferenciam uma metodologia um tanto desafiadora, que é a transdisciplinaridade, provocam uma visão inovadora ao se deparar com a participação e o interesse da parte do docente em buscar assimilar a sua disciplina com as outras, instigados pelo desafio e pelo intuito de fazer acontecer algo que sEJA considerado desfragmentado pelas disciplinas em geral. Ao se trabalhar com a EJA, essas percepções tornam-se muito mais evidentes, pois o conhecimento de mundo e as experiências já vividas contribuem para uma assimilação entre o aprendizado teórico e aquilo que já se vive considerando o indivíduo como cidadão crítico e conhecedor de vários saberes que se compartilha transformando-os em saber científico. A participação dos professores nesta etapa do desenvolvimento dos alunos é de suma importância, pois ele instiga o aluno a desenvolver e a exercer sua autonomia crítico/reflexiva/participativa na sociedade em que está inserido. Para Behrens (2008):

A sociedade do conhecimento demanda repensar a educação, a prática pedagógica dos professores, de modo a pensar na formação de cidadãos para agir com responsabilidade, e nessa perspectiva, os processos ensinoaprendizagem convergem para o preparo da comunidade acadêmica no sentido de refletir, analisar e buscar construir projetos pedagógicos crítico, reflexivos e transformadores que levem à formação do ser humano, com uma visão de mundo mais igualitária, solidária, justa e fraterna. 
Realizados os propósitos desta intervenção, a mesma equipe voltou a se reunir para socializarem os seus depoimentos a respeito das experiências metodológicas acima citadas, sendo assim, ao analisarem e experimentarem o material sugerido como instrumento de fonte de informação e, com isso, gerando compartilhamento de saberes, tanto do corpo educacional quanto no conjunto com os alunos, a equipe envolvida se surpreendeu com o trabalho proposto de forma a já se lançarem em busca de novos conceitos a se trabalhar com o mesmo propósito e, chegando a uma definição de tema, o que fortalece o propósito desafiador da intervenção realizada. Em conformidade com o relato segue em anexo o relatório dos professores.

\section{Considerações finais}

Quando os estagiários optaram por uma proposta desafiadora como esta, ficou evidente a incerteza do seu sucesso. Até mesmo por se tratar de um assunto que foge um pouco às opções comumente exploradas por outros estagiários e até alguns docentes por estarem sujeitados a uma prática educativa historicamente bancária, fruto de uma formação inicial positivista e cartesiana e gerando obstáculos na formação continuada. Mas, buscando colocar em prática tal proposta, procurou-se parceria junto com a Escola Estadual de Ensino Fundamental e EJA Antonio José de Lima para fazer acontecer e, unanimemente, concordaram em participar deste momento como prática interventiva dos estagiários.

Ao iniciarem as participações utilizando o recurso indicado, aconteceram algumas resistências por parte dos alunos por se tratar do mesmo material, mas ao perceberem que isso fazia parte do seu dia a dia, interagiram satisfatoriamente e os professores perceberam que tinham em mãos um material muito rico como fonte de estudo e trabalho.

Os professores que trabalham com esta modalidade de ensino foram levados a uma reflexão, a um repensar metodológico em como um material visto como comum, guardasse em si uma vasta quantidade de conhecimentos a serem explorados incitando-os a planEJAr outros temas, outros momentos para elaboração de um novo trabalho.Os alunos que fizeram parte deste grupo de interação do senso comum com o científico, se viram envolvidos com uma experiência que muito se assemelhava com os seus viveres. Viveres em humildade, mas dotados de grande sabedoria quando puderam assimilar com facilidade suas realidades com a cientificidade e puderam 'compartilhar os saberes'.

Analisando todo o período em que foi utilizado o panfleto como instrumento pedagógico para provocar a transdisciplinaridade, os professores ficaram satisfeitos com o trabalho realizado e, em reunião, socializando suas experiências, se propuseram a buscar outro material, ou mesmo alternativa do cotidiano para trabalharem de forma transdisciplinar.

A transdisciplinaridade ultrapassa sutilmente a barreira entre senso comum e o científico de maneira muitas vezes imperceptível a muitos olhares. Segundo a Revista Práxis (2012) "Porém, uma das fronteiras de maior destaque que a educação científica tem para superar, é o saber fragmentado, que ainda é uma realidade entranhada no meio educacional."

Neves (1998, p.78) diz:

O que temos vistos nas ultimas décadas é a ciência sendo aprendida como um dado e não como uma possibilidade
de construção e integração com as demais ciências e com as necessidades diárias do cidadão comum'. Percebemos
que essa fragmentação ocorre não devido somente ao despreparo do professor, mas também devido a ausência de
materiais didáticos que apresentem propostas concretas e não camufladas de um ensino de ciência de forma
integrada, sendo perceptível as relações inter e transdisciplinares existentes no universo do conhecimento
cientifico.

Em observância a toda essa experiência desafiadora em apresentar uma proposta pedagógica envolvendo toda a equipe escolar e em concordância com a mesma, segundos os relatos apresentados pelos docentes e com os objetivos propostos neste trabalho pode se assim dizer, numa análise geral e qualitativa, que o rendimento do trabalho correspondeu às expectativas através dos resultados 
observados pela dinâmica, com os alunos, da trilha pedagógica e relatórios apresentados pelos docentes, o que responde a problemática apresentada como algo que provocou a proposta deste trabalho.

A proposta de usar o panfleto publicitário como material pedagógico veio a contribuir até mesmo para atender a uma solicitação do Centro de Formação e Aperfeiçoamento dos Profissionais da Educação -CEFAPRO - Rondonópolis que havia encaminhado a orientação à Escola para que elaborasse trabalhos onde pudessem desenvolver suas habilidades docentes a partir de materiais comuns aos alunos como fonte de pesquisa e informações, assimilando os seus ricos conhecimentos prévios com a cientificidade existente em cada material. Nesse momento gera uma troca de experiência onde todos aprendem, tanto professor, como equipe gestora e alunos, até mesmo por que essa experiência contribuiu para a descoberta que essa prática é construída com diálogos e troca de experiências entre os professores, o que os leva a pensar em novas formas de elaborar e buscar materiais didáticos onde se possa valorizar e desenvolver suas potencialidades - tanto o professor quanto o aluno.

Utilizando este instrumento pedagógico para e no ensino de Ciências, é notória a importância de aproveitar novas propostas e pesquisas para se aproximar cada vez mais as ciências do dia a dia das pessoas, na busca de interação e integração com os meios. A parceria ocorrida entre os estagiários e as equipes gestora e docente contribuiu para enriquecer ambas as partes ampliando suas visões, suas potencialidades, suas percepções como instigadores de conhecimentos.

A transdisciplinaridade foi observada no decorrer do processo metodológico, pois se trata de atitudes, ações da comunidade envolvida na realização do processo ensino/aprendizagem, ou sEJA, aquilo que se denomina práxis pedagógica.

Ao contato com o Projeto Político Pedagógico, fazendo uma leitura analítica, torna-se necessário registrar simbolicamente, aqui uma 'moção de aplauso' à Equipe Gestora da referida escola porelaborar um documento onde é perceptível a preocupação em fazer acontecer uma educação democrática onde os alunos são os principais personagens, em suas realidades, visando assim respeitar suas histórias, seus conhecimentos, suas possibilidades.

\section{Agradecimentos}

À Coordenação de Aperfeiçoamento de Pessoal de Nível Superior (CAPES) pelo subsídio através do Programa de Consolidação das Licenciaturas (PRODOCENCIA) Edital 019/2013, processo № 113.657, e do Programa Institucional de Bolsa de Iniciação à Docência (PIBID) Edital № 061/2013, processo № 128.570, IFMT/Campus São Vicente/Sub Projeto Ciências.

\section{Referências}

Antonio, S. Educação e transdisciplinaridade: a necessidade de uma nova escuta poética, Editora Lucerna, Rio de Janeiro-RJ, 2002.

Behrens, M. A. Paradigma da Complexidade: Metodologia de Projeto, Contratos e Portfólios. 2.ed. Petrópolis, RJ: Vozes, 2008.

Brasil. Secretaria de Educação Fundamental. Parâmetros Curriculares Nacionais: Ciências Naturais. Brasília: MEC/SEF, 1997.

Freire, P. Pedagogia da Autonomia: saberes necessários à prática educativa. Editora Paz e Terra, São Paulo-SP, 1996 (Coleção Leitura). 
Galdino M. Transdisciplinaridade na revista Nova Escola, muito bom viu!Disponível em:<http://xuxugaldino.blogspot.com.br/2008/05/transdisciplinaridade-na-revista-nova.html >Acesso em: 17 ago. 2014.

LopesS.P. ; Sousa L.S.EJA: uma educação possível ou mera utopia? São Paulo: Disponível em: .<http://www.cerEJA.org.br/pdf/revista v/revista selvaplopes.pdf > Acesso em: 22 jul. 2014.

Moura, D. H.; Baracho, M. G. (orgs). Natal: IFRN Editora, 2010. P. 13-36.

Nicolescu, B. Manifesto da Transdisciplinaridade. São Paulo: Trion, 1999, 167p.

Projeto Político Pedagógico, 2010, Escola Estadual de 1ํGrau Antônio José de Lima. REVISTA PRÁXIS, ano IV, nº 8 - agosto, 2012.

Santos A. O que é transdisciplinaridade. Disponível em: $<$ http://www.ufrri.br/leptrans/arquivos/O QUE e TRANSDISCIPLINARIDADE.pdf> Acesso em: 16 ago. 2014.

Silva, M.M. A. de; Henrique, A. L. S. Concepções de professores sobre os desafios da docência no PROEJA no IFRN: práticas pedagógicas e formação docente.

Weil, P; et al. Rumo à nova transdisciplinaridade: sistemas abertos de conhecimento. Editora Summus, São Paulo-SP, 1993. 